\title{
STANDARISASI PRODUK HANGER BAJU DI DESA WANENGPATEN KEDIRI MELALUI PEMELIHARAAN KONSISTENSI MUTU UNTUK MENINGKATKAN DAYA SAING
}

\author{
Imam Safi’i 1), Lolyka Dewi Indrasari 2), Silvi Rushanti Widodo 3) \\ 1Fakultas Teknik,Universitas Kadiri \\ imam@unik-kediri.ac.id \\ ${ }_{2}$ Fakultas Teknik, Universitas Kediri \\ lolyka@unik-kediri.ac.id \\ 3Fakultas Teknik,Universitas Kadiri \\ silvi@unik-kediri.ac.id
}

\begin{abstract}
Abstrak
Tingkat persaingan produk hanger baju kini mulai bermunculan. Melihat kondisi ini produk harus dituntut berkualitas agar produk dapat lebih diminati oleh konsumen dan diterima dipasaran. Melihat permasalahan yang dihadapi para pelaku produksi hanger baju, maka perlu dilakukan suatu langkah awal dengan kegiatan penyuluhan kepada pelaku usaha hanger baju mengenai pentingnya menjaga kualitas produk dan melahirkan standar mutu sehingga nantinya produk tersebut mampu memiliki daya saing dengan produk lain dan bisa masuk ke pasar modern. Tujuannya agar kesadaran kualitas pelaku produksi hanger baju meningkat dengan melihat fenomena yang terjadi di luar. Metode yang digunakan dalam kegiatan pengabdian masyarakat ini adalah pendidikan masyarakat melalui ceramah, simulasi dan diskusi. Dari ceramah dan diskusi yang terjadi dapat disimpulkan bahwa cacat produk dalam hanger baju yang sering terjadi adalah tidak samanya ukuran produk, kelonggaran pada ikatan uliran, material mudah berkarat, gampang berubah bentuk (tidak presisi), produksi hanger baju masih memakai mesin mekanik atau konvensional yang dimana konsistensi mutu disini sering berubah, produk hanger baju belum memiliki cap merek yang kurang menarik, pelaku masih sering mendapat permasalahan mengenai permodalan dalam proses produksi. Solusi yang bisa diberikan kepada masyarakat adalah membuat standar mutu produk, bantuan sarana dan prasarana pendukung, packing yang menarik, pengetahuan mengenai pembuatan siklus permintaan.
\end{abstract}

Kata Kunci: persaingan, kualitas, pendidikan masyarakat. 


\section{Pendahuluan}

Desa Wanengpaten termasuk salah satu wilayah di Kecamatan Gampengrejo Kabupaten Kediri dengan Luas $0.72 \mathrm{~km} 2$ dari total luas Kecamatan sebesar $19.89 \mathrm{~km} 2$ dan termasuk klasifikasi Pedesaan dengan jumlah penduduk total 2610 jiwa diantaranya 1309 berjenis kelamin laki-laki dan 1301 berjenis kelamin perempuan (BPS 2017). Desa Wenengpaten merupakan desa yang mempunyai produk unggulan diantaranya pada tahun 2016 yaitu Roti Ketepeng dan Hanger Baju.

Hanger baju atau bisa juga disebut gantungan baju pertama kali diperkenalkan oleh Presiden Thomas Jeffersen yang terbuat dari bahan kayu, Tetapi, sekarang yang kita banyak pakai yaitu gantungan yang terbuat dari besi yang diciptakan oleh Albert J. Parkhouse. Pada tahun 1903. Parkhouse mengambil sepotong kawat, membengkokkannya manjadi dua lingkaran lonjong berlawanan satu sama lain, dan memutar kedua ujungnya kembali membentuk sebuah pengait (www.thoughtco.com). Gantungan yang Parkhouse buat akhirnya dipatenkan pada 25 Januari 1904, tetapi ia masih mengembangkannya yang lalu ia patenkan kembali pada tahun 1907. Pada tahun 1906, Meyer May adalah penjual baju pertama dengan merek Grand Rapids di Michigan yang menggunakan gantungan baju untuk menampilkan dagangannya (www.ideafinder.com).

Jadi hanger baju yang dibuat di Desa Wenengpaten melanjutkan pembuatan dari sejarah produk hanger tersebut diatas. Jumlah yang memproduksi hanger di Desa Wenengpaten adalah 8 rumah tangga. Karena memang skala belum besar, dikarenakan awal terbentunya usaha ini dimulai sekitar tahun 2003 dan turun temurun sampai ke anak cucunya. Yang lebih unik disini dari produksi hanger baju pada umumnya, adalah penggunaan bahan baku. Bila secara umum oraang memproduksi produk barang memerlukan bahan baku yang baru, hanger baju di Desa Wenengpaten menggunakan bahan baku dari limbah industri dari PT. Zig Zag yang berada tidak jauh dari lokasi desa tersebut. Limbah industri yang dimaksud adalah dari bongkaran pallet kertas yang dimana ada kawat yang mengikatnya, kawat inilah yang kemudian dibeli oleh masyarakat Desa Wenengpaten untuk diolah lagi menjadi produk hanger baju.

Seiring berjalannya produksi hanger baju tersebut, tingkat persaingan produk sejenis kini mulai bermunculan dan beberapa desa disekitarnya juga mulai memproduksi hanger baju. Melihat kondisi ini jelas produk harus ditutut berkualitas agar produk dapat lebih diminati oleh konsumen dan diterima dipasaran. Kualitas merupakan kondisi dinamis yang berhubungan dengan produk, jasa, manusia, proses dan lingkungan yang memenuhi atau melebihi harapan (Tjiptono. 2000;51). Pada masa sekarang, kualitas tidak hanya merupakan 
usaha untuk memenuhi persyaratan spesifikasi yang telah ditentukan atau usaha untuk mengurangi produk yang rusak, tetapi lebih luas dari hal tersebut. Kualitas merupakan usaha menyeluruh yang meliputi setiap usaha perbaikan organisasi dalam memuaskan pelanggan (Bounds, 1994). Jika melihat definisi tersebut maka dapat disimpulkan bahwa kualitas merupakan standar mutu dimana setiap unsur saling berhubungan dan mempengaruhi kinerja harapan pelanggan. Disini Standarisasi dalam produksi hanger baju di Desa Wenengpaten memang belum sama sekali diterapkan, masyarakat hanya berpikir bahan baku ada dan bagaimana bisa berproduksi untuk memenuhi permintaan tanpa menerapkan standar mutu.

Melihat permasalahan yang dihadapi para pelaku produksi hanger baju di Desa Wenengpaten ini, maka perlu dilakukan suatu langkah awal dengan kegiatan penyuluhan kepada pelaku usaha hanger baju di Desa Wenengpaten mengenai pentingnya menjaga kualitas produk dan melahirkan standar mutu sehingga nantinya produk tersebut mampu memiliki daya saing dengan produk lain dan bisa masuk ke pasar modern. Tujuannya agar kesadaran kualitas pelaku produksi hanger baju meningkat dengan melihat fenomena yang terjadi di luar.

\section{Metode Pelaksanaan}

Metode yang digunakan dalam kegiatan pengabdian masyarakat ini adalah pendidikan masyarakat melalui ceramah, simulai dan diskusi yang dilaksanakan tanggal 17 Juli 2017 dimulai pukul 10.00 WIB sampai selesai bertempat di Balai Desa Wanengpaten kec. Gampengrejo Kab. Kediri. Media dan bahan yang digunakan adalah LCD proyektor serta materi ringkas mengenai pengendalian kualitas dan standar mutu produk hanger yang diberikan ke masyarakat khususnya pelaku produsen hanger baju di Desa Wenengpaten. Ceramah dilakukan kurang lebih 1 sks skitar 50 menit selanjutnya dilakukan diskusi bersama warga untuk memunculkan permasalahan dan mencarikan solusinya.

\section{Hasil dan Pembahasan}

Melihat peluang produk hanger baju di Desa Wenengpaten ini memang masih menjanjikan, dikarenakan adanya permintaan hanger oleh rumah tangga muda dan para usaha laundry. Namun ancaman diluar selain bermunculan produksi sejenis, inovasi bentuk fisik hager baju serta mesin otomatis pembuat hanger baju sudah banyak bermunculan. 


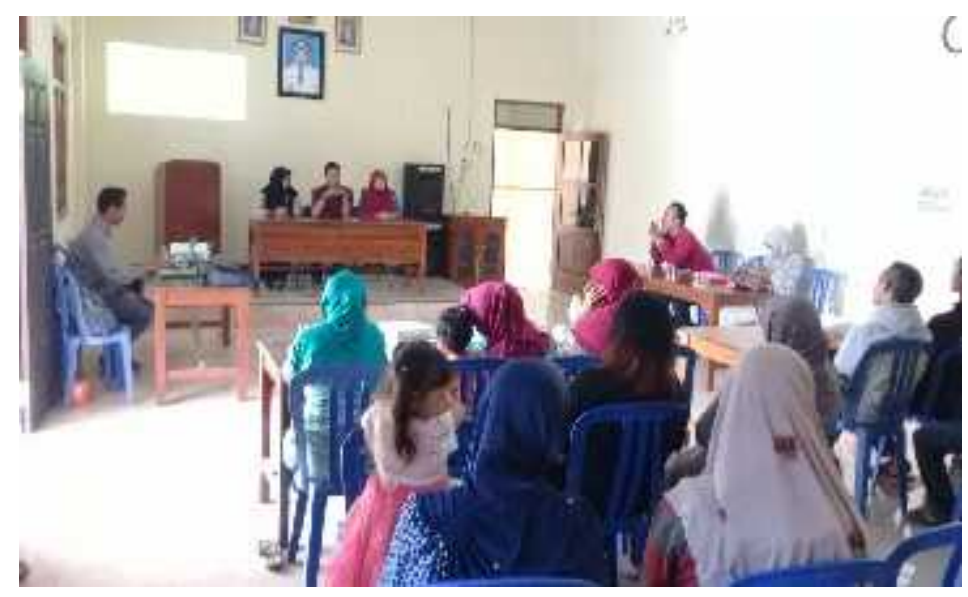

Gambar 1. Ceramah kepada Masyarakat Produsen Hanger Baju

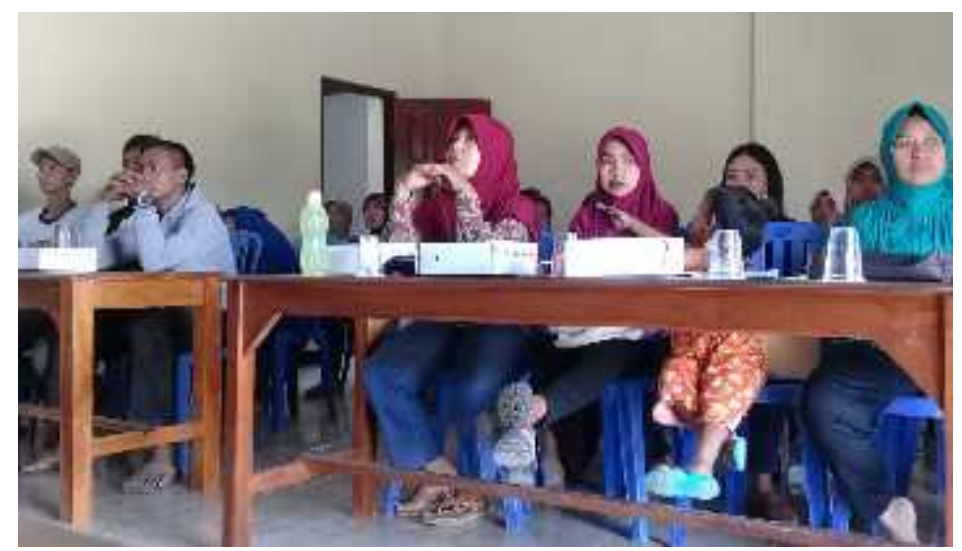

Gambar 2. Masyarakat Produsen Hanger Baju

Dari ceramah dan diskusi yang terjadi dapat disimpulkan bahwa 1) Cacat produk dalam hanger baju yang sering terjadi adalah tidak samanya ukuran produk, kelonggaran pada ikatan uliran, material mudah berkarat, gampang berubah bentuk (tidak presisi). 2) Produksi hanger baju masih memakai mesin mekanik atau konvensional yang dimana konsistensi mutu disini sering berubah. 3) Produk hanger baju belum memiliki cap merek yang kurang manarik. 4) Pelaku masih sering mendapat permasalahan mengenai permodalan dalam proses produksi, ini bisa disebabkan tidak adanya informasi mengenai ramalan permintaan produk. Jika melihat dari permasalahan yang telah didiskusikan, maka solusi yang bisa diberikan kepada masyarakat adalah : 1) Membuat standar mutu produk kemudian memberikan pelatihan rutin terhadap karyawan di lantai produksi, serta adanya pengendalian mutu atau inspeksi. 2) Perlu bantuan sarana dan prasarana pendukung seperti mesin otomatis yang dimana akan meningkatkan jumlah produksi serta kualitas produk. 3) Diperlukan packing yang menarik sehingga diharapkan mampu diterima di supermarket yang biasanya memiliki persyaratan khusus untuk packing produk. 4) Produsen diajari mengenai pembuatan siklus 
permintaan dengan mendata jumlah permintaan waktu sebelumnya terlebih dahulu, karena dilapangan diutarakan oleh masyarakat yang memproduksi hanger baju hampir tidak pernah menulis data mengenai jumah pemesan setiap bulan dan ini berdampak saat modal sedikit untuk membeli bahan baku, sedangkan saat itu jumlah permintaan banyak, maka permaslah modal akan muncul, juga diberikan pelatihan mengenai pengendalian persediaan bahan baku agar stock bahan baku terpenuhi saat melakukan produksi.

Pada produk hanger secara umum memimiliki Hasil pengabdian kepada masyarakat yang telah dilakukan adalah : 1) Pelaku produsen pembuat hanger baju belum memiliki kesadaran mengenai standar mutu

\section{Daftar Pustaka}

Badan Pusat Statistik. (2017). Gampengrejo Subdistrict in figures. BPS Statistik of Kediri Regency.

Bellis, Marry. (2017). The Invention of the Coat Hanger. https://www.thoughtco.com/whoinvented-the-coat-hanger-4070933, diakses pada 30 November 2017.

Bounds, Greg. (1994). Beyond Total Quality Management, toward the emerging paradigm, Mc. Graw Hill Int. Edition.

Parkhouse,

Albert.

(1903).

Wire

Coat

Hanger.

http://www.ideafinder.com/history/inventions/coathanger.htm, diakses pada 30 November 2017.

Tjiptono, Fandy. (2000). Manajemen Jasa. Penerbit Andi Yogyakarta. 